\title{
Coagulation profile in two nephropathic dogs
}

M. V. Anjaly*1, K. R. Sindhu², N. P. Usha ${ }^{3}$, S. Ajithkumar ${ }^{4}$ and K. Justin Davis ${ }^{5}$ Department of Veterinary Clinical Medicine, Ethics and Jurisprudence, College of Veterinary and Animal Sciences, Mannuthy, Thrissur, Kerala 680651 Kerala Veterinaray and Animal Sciences University, Kerala, India.

Citation: Anjaly, M. V., Sindhu, K. R., Usha, N. P., Ajithkumar, S. and Justin Davis, K. 2021. Coagulation profile in two nephropathic dogs. J. Vet. Anim. Sci. 52(4):409-413

DOI: https://doi.org/10.51966/jvas.2021.52.4.409-413

Received:08.03.2021

Accepted: 30.05 .2021

Published:15.12.2021

\section{Abstract}

Coagulatory abnormalities are common in renal dysfunction in humans. The studies on coagulatory abnormalities in renal failure in dogs are limited. The present paper deals with coagulation profile in acute and chronic kidney disease in dogs. The haemostatic defects observed in acute renal dysfunction included thrombocytopaenia, prolonged capillary bleeding time $(C B T)$, elevated D-Dimer and hypoantithrombinemia which indicated a hypercoagulable state. Prolongation of prothrombin time (PT), activated partial thromboplastin time (aPTT), elevated $D$-Dimer concentration and hypoantithrombinemia in chronic kidney disease indicated the presence of hypocoagulable state.

Key words: Coagulation profile, nephropathy, dog

Haemostasis could be defined as a complex process of blood clot formation at the site of vascular damage. The haemostatic system is in a balance between procoagulant factors and anticoagulants. Any imbalance in these factors could result in thrombosis or bleeding. Haemostatic abnormalities in renal diseases are common but not widely studied in dogs. The present paper deals with haemostatic defects in two nephropathic dogs presented to the University Veterinary Hospital, Mannuthy.

The first case was a one year old male Rottweiler dog with a history of viper envenomation four days prior to presentation of the animal in the hospital . The animal was treated with antivenom, Vitamin $\mathrm{K}$ and prednisolone at a near by veterinary hospital. The owner reported that the animal was not taking food and water even after the treatment. The owner observed vomiting, red colured urine and reddish spots on the abdomen on the day prior to the presentation. The second case was a nine year old female Labrador retriever with a history of anorexia, black-coloured feaces, anuria, vomiting and blood streaks from mouth since five days.

"Part of MVSc thesis submitted to Kerala Veterinary and Animal Sciences University, Pookode, Wayanad, Kerala

1. MVSc Scholar

2. Assistant Professor

3. Professor and Head

4. Professor and Head, Department of Veterinary Clinical Medicine, Ethics and Jurisprudence, CVAS, Pookode

5. Assistant Professor, Department of Veterinary Epidemiology and Preventive Medicine

${ }^{*}$ Corresponding author:email-anjaly01@gmail.com,Ph: 8111828753

Copyright: (C) 2021 Anjaly et al. This is an open access article distributed under the terms of the Creative Commons Attribution 4.0 International License (http://creativecommons.org/licenses/by/4.0/), which permits unrestricted use, distribution, and reproduction in any medium, provided the original author and source are credited. 
Upon examination of the first case with the history of viper envenomation, the animal was dull and depressed. The whole blood was clotted within $20 \mathrm{~min}$. Edema on the eyelids (Fig. 1) and right forelimbs, congested mucous membrane, petechiae (Fig. 2), haemoglobinuria, hyperventilation and anuria was also recorded.whereas in the latter case, ulcerations on the buccal mucosa (Fig. 3), hypersalivation, melena, respiratory distress, congested mucous membrane and subnormal temperature were observed. The haematobiochemical values were represented in the table 1.

Echinocytes and schistocytes were observed in acute kidney injury on blood smear evaluation. On ultrasonography, increased cortical echogenicity of the left kidney (Fig. 4) and splenomegaly was observed in first case with snake envenomation. No corticomedullary distinction with irregular contour of kidney was found in the second case.

Based on the findings such as history, clinical signs, ultrasonographic findings, haematology and serum biochemistry, the first case was diagnosed as acute kidney injury and second case as chronic kidney disease.

Treatment was initiated with Amoxicillin-sulbactum @ 12.5 mg/ kg BW IV BID, proton pump inhibitors (Pantoprazole @ 1 $\mathrm{mg} / \mathrm{kg} \mathrm{BW}$, IV OD ), antiemetics (Ondensetron @ $0.5 \mathrm{mg} / \mathrm{kg}$ IV BID), B complex and fluids for both the cases for two days. Darbepoeitin injection at the rate of $0.25 \mu \mathrm{g} / \mathrm{kg}$ BW SC once was given for chronic renal failure case. Animal diagnosed with chronic kidney disease died on the day two of treatment. The animal with acute kidney injury was advised for dialysis and was not presented for further treatment. The owner reported that the animal died after one week of presentation.

Table 1.Haematobiochemical and coagulation changes of nephropathic dogs

\begin{tabular}{|l|c|c|c|}
\hline \multicolumn{1}{|c|}{ Parameters } & Control & Case I & Case II \\
\hline Total erythrocyte count $\left({ }^{*} 10^{6} / \mathrm{cmm}\right)$ & $6.36 \pm 0.25$ & 3.81 & 3.76 \\
\hline Haemoglobin $(\mathrm{g} / \mathrm{dL})$ & $13.06 \pm 0.5$ & 9.1 & 6.7 \\
\hline VPRC $(\%)$ & $35.81 \pm 0.19$ & 21.5 & 16.9 \\
\hline MCV $(\mathrm{fL})$ & $66.00 \pm 1.21$ & 56.4 & 44.9 \\
\hline MCH $(\mathrm{pg})$ & $21.56 \pm 0.68$ & 23.9 & 17.6 \\
\hline MCHC $(\mathrm{g} / \mathrm{dL})$ & $33.95 \pm 0.81$ & 42.3 & 39.6 \\
\hline Total leukocyte count $\left({ }^{*} 10^{3} / \mathrm{cmm}\right)$ & $10.31 \pm 1.21$ & 26.5 & 7.8 \\
\hline Total neutrophil count $\left({ }^{\star} 10^{3} / \mathrm{cmm}\right)$ & $7.23 \pm 1.05$ & 21.5 & 5.2 \\
\hline Total platelet count $\left({ }^{*} 10^{3} / \mathrm{cmm}\right)$ & $266.50 \pm 28.49$ & 17 & 48 \\
\hline MPV $(\mathrm{fL})$ & $7.51 \pm 0.14$ & 6.5 & 6.8 \\
\hline PCT $(\%)$ & $0.20 \pm 0.02$ & 0.012 & 0.02 \\
\hline PDW $(\%)$ & $14.98 \pm 0.16$ & 11.4 & 13.2 \\
\hline ALT $(\mathrm{U} / \mathrm{L})$ & $46.83 \pm 4.07$ & 228.1 & 97.1 \\
\hline ALP $(\mathrm{U} / \mathrm{L})$ & $147.73 \pm 26.16$ & 540 & 659.5 \\
\hline Total protein $(\mathrm{g} / \mathrm{dL})$ & $5.71 \pm 0.29$ & 4.03 & 4.3 \\
\hline Albumin $(\mathrm{g} / \mathrm{dL})$ & $2.95 \pm 0.10$ & 1.25 & 1.9 \\
\hline Globulin $(\mathrm{g} / \mathrm{dL})$ & $2.76 \pm 0.22$ & 2.78 & 2.4 \\
\hline Creatinine $(\mathrm{mg} / \mathrm{dL})$ & $0.90 \pm 0.01$ & 11.9 & 26.8 \\
\hline CBT $(\mathrm{min})$ & $0.40 \pm 0.03$ & 3.3 & 6 \\
\hline PT $(\mathrm{sec})$ & $8.5 \pm 0.66$ & 12.2 & 15 \\
\hline aPTT $(\mathrm{sec})$ & $15.46 \pm 1.6$ & 19.9 & 23 \\
\hline ACT $(\mathrm{sec})$ & $60 \pm 7.7$ & 90 & 150 \\
\hline FDPs $(\mu \mathrm{gg} / \mathrm{mL})$ & $0.93 \pm 0.26$ & 2.415 & 2.92 \\
\hline D-Dimer $(\mathrm{ng} / \mathrm{mL})$ & $58.41 \pm 8.60$ & 157 & 193 \\
\hline AT III $(\mathrm{ug} / \mathrm{mL})$ & $222.56 \pm 34$ & 109 & 26 \\
\hline
\end{tabular}


Detailed study were conducted in the cases to assess the coagulation status of animals based on platelet morphology and coagulation parameters such as capillary bleeding time (CBT), prothrombin time (PT), activated partial thromboplastin time (aPTT), activated coagulation time (ACT), D-Dimer (DD), FDPs and antithrombin III (AT III) concentration (Table 1).

In the first case with the history of viper envenomation, the acute kidney injury could be due to the renal ischemia secondary tohaemorrhage, hypotension, intravascular haemolysis, enzymatic activities in venom and rhabdomyolysis. Chronic renal failure in the second case might be due to the progressive long standing renal injury which affected all the renal compartments. Microcytic anaemia and hypoproductive thrombocytopaenia observed in nephropathic cases could be due to the erythropoietin deficiency in chronic kidney disease (Rubin and Carr, 2007) or due to the venom mediated bone marrow depression in acute kidney injury (Trompoukiet al., 2017).

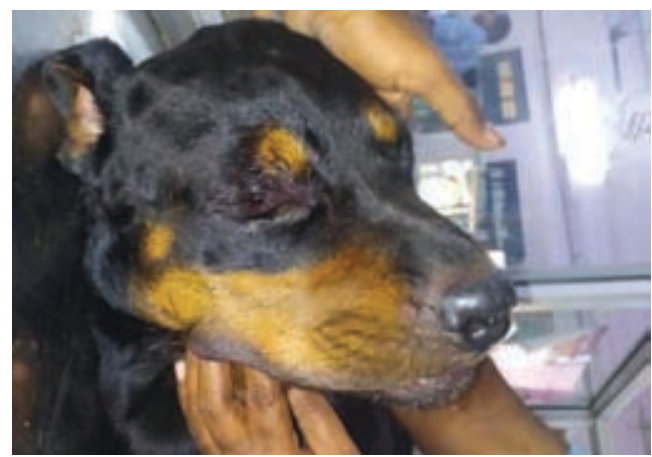

Fig. 1. Swelling of face and eyelids

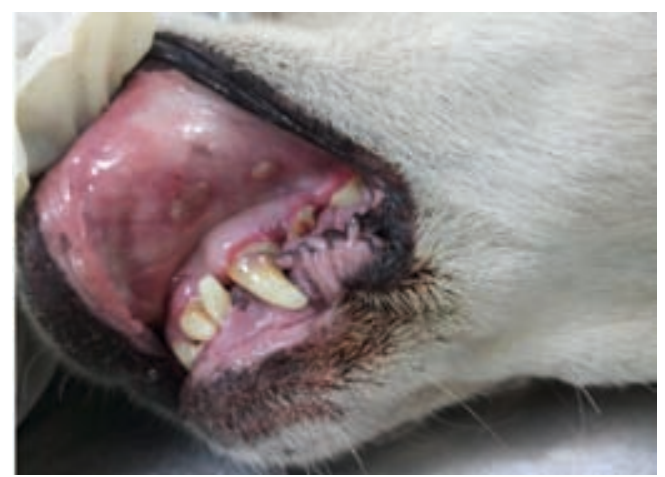

Fig. 3.Ulceration of buccal mucosa
Neutrophilic leukocytosis observed in acute renal failure of this studywas in accordance with Nagel et al. (2014) who reported that these changes might be associated with cellular damage, inflammatory changes and cytokine release. Serumbiochemisry changes observed in these cases were similar to Polzin et al. (2000) who observed increased creatinine level, hypoproteinemia, hypoalbuminemia and low $A / G$ ratio in renal dysfunction.

The sonographic findings in chronic renal failure were similar to Kumar et al. (2011) who reported that small sized kidneys without clear architecture could occur in chronic kidney disease. The most common finding during ultrasound inacute kidney failure was cortical hyperechogenicity which was in accordance with Ozmen et al. (2010).

The haemostatic defects observed in nephropathic cases were similar to Dorgalaleh et al. (2013) and Mcbride et al. (2019) who observed thrombocytopaenia, abnormal BMBT and uraemic bleeding in renal

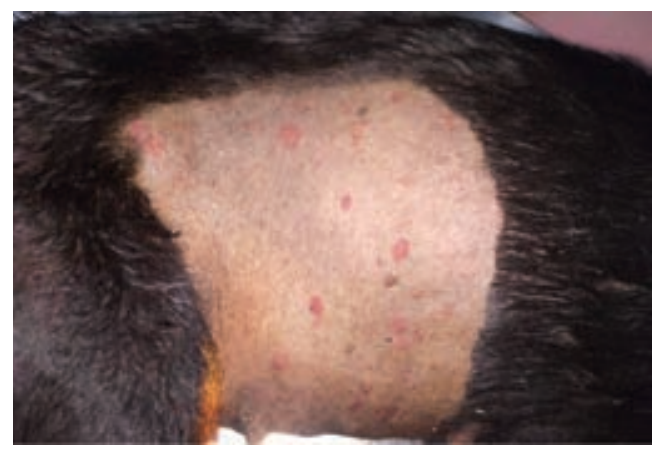

Fig. 2. Ecchymotic areas in lateral abdomen

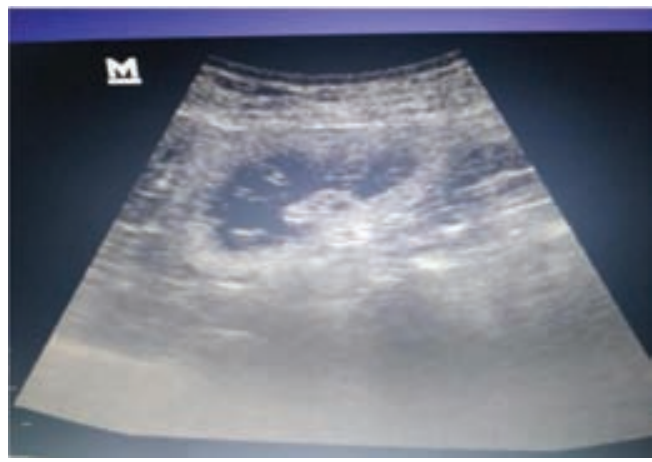

Fig. 4. Increased cortical echogenecity 
dysfunction. Compared to the acute renal injury, CBT, PT, aPTT, D-Dimer concentration were more elevated in the chronic kidney disease of this study. The prolonged CBT observed in both these cases might be due to thrombocytopaenia or platelet dysfunction (Mischke, 2014). In acute kidney injury, severe thrombocytopenia with normal PT, aPTT indicated the absence of consumption of clotting factors. Absence of consumption of clotting factors could be due to the prior antivenom treatment (Nayankumar, 2016). But the elevated D-Dimer levels and hypoantithrombinemia recorded in the acute kidney injury could indicated the procoagulant state which increased the risk for developing thrombotic events. Hence the presence of elevated D-Dimer, hypoantithrombinemia, normal PT, aPTT in acute kidney injury indicated the presence of hypercoagulable state (Huang et al., 2017). Presence of prolonged PT, aPTT, elevated D-Dimer and hypoantithrombinemia observed in chronic case indicated a hypocoagulable status.

Thrombocytopaenia was severe in acute kidney injury and moderate in chronic kidney disease. Shistocytes and thrombocytopaenia observed in acute kidney injury due to viper envenomation was in accordance with Vikrant et al. (2017) who reported that these findings could indicate microvascularangiopathy secondary to vasculitis. Echinocytes observed in the study was in aggrement with Nayankumara (2016) who reported that phospholipase A2 mediated red blood cell membrane alteration resulted in the formation of echinocytes. Phospholipase A2 in viper venom might cause damage to the platelets, erythrocyte membrane and vascular endothelium and subsequently microangiopathy. Echinocytes observed in chronic kidney disease could be due to dehydration.

Paucity exists in the literature regarding coagulopathic analysis in canine renal diseases. In human patients with stage IV renal failure had thrombocytopaenia, elevated levels of D-Dimer concentration, prolonged bleeding time, prolonged PT and aPTT whereas in stage III renal failure, patients had a normal bleeding time, PT and aPTT but elevated D-Dimer concentration and low platelet count
(Shah, 2013). The observation noticed in stage IV by Shah(2013) were similar to chronic kidney disease observed in the present study. The observation noticed in stage III were seen in acute renal injury.

In this study, the D-Dimerconcentration observed on the day of presentation in chronic renal failure case was different from disseminated intravascular coagulation criteria (<250 ng / mL).But the guarded prognosis observed in chronic renal failure case could be due to the progression of hypocoagulable state further.

\section{Summary}

Based on the findings, haemostatic defects in acute renal failure included thrombocytopaenia, platelet dysfunction and elevation of D-Dimerandhypoantithrombinemia. These observations indicated that the existence of a hypercoagulable state which could lead to thrombotic events in acute renal failure. Wheras in chronic renal failure, prolonged PT, aPTT, elevation of D-Dimer and hypoantithrombinemia indicated the presence of hypocoagulable state.

\section{Conflict of interest}

The authors declare that they have no conflict of interest.

\section{References}

Dorgalaleh, A., Mahmudi, M., Tabibian, S., Khatib, Z. K., Tamaddon, G. H., Moghaddam, E.S., Bamedi, T., Alizadeh, S. and Moradi, E. 2013. Anemia and thrombocytopenia in acute and chronic renal failure. Int. J. Hematol. Stem. Cell Res. 7: 34-39.

Huang, M.J., Wei, R.B., Wang, Y., Su, T.Y., Di, P., Li, Q.P., Yang, X., Li, P. and Chen, X.M., 2017. Blood coagulation system in patients with chronic kidney disease: a prospective observational study. B. M. J.open 7: 1-7.

Kumar, V., Kumar, A. and Varshney, A. C. 2011. Ultrasonographic Imaging for Structural Characterization of Renal Affections and 
Diagnosis of Associated Chronic Renal Failure in 10 Dogs. I. S. R. N. Vet. Sci. 2011: 1-11.

Mcbride, D. J. R. E., Stefano, C and chan, D. L. 2019. Primary hemostatic function indogs with acute kidney injury.J. Vet. Int. Med.33: 2029-2036.

Mischke, R., 2014. Laboratory evaluation and interpretation of haemostasis in small animals. J. Hellenic Vet. Med. Soc. 65: 165-180.

Nagel, S.S., Schoeman, J.P., Thompson, P.N., Wiinberg, B. and Goddard, A. 2014. Hemostatic analysis of dogs naturally envenomed by the African puffadder (Bitis arietans) and snouted cobra (Naja annulifera). J. Vet. Emerg. Crit. Care. 24: 662-671.

Nayanakumara, S. 2016. Clinico-pathologicalin vestigationsonsnakeenvenomationindo gs. MVSc thesis, KeralaVeterinaryandA nimalSciencesUniversity. Pookode. 88p.

Ozmen, C. A., Akin, D., Bilek, S. U., Bayrak, A. H., Senturk, S. and Nazaroglu, H. 2010. Ultrasound as a diagnostic tool to differentiate acute from chronic renal
failure.Clin.Nephrol.74: 46-52.

Polzin, D. J., Osborne, C. A., Jacob, F and Ross, S. 2000. Chronic renal failure.In: Ettinger, S. J. and Feldman, E. C. (ed.), Textbook of Veterinary Internal Medicine: Diseases of the Dog and Cat. (2 $2^{\text {nd }}$ Ed.). Elsevier Saunders, Philadelphia, pp.1734-1760.

Rubin, S. I. and Carr, A. P. 2007.Canine Internal Medicine Secrets.(1 ${ }^{\text {st }}$ Ed.). Elsevier, Missouri, 464p.

Shah, S.A., 2013. Haemostatic defects in chronic kidney disease. J. Med. Sci. 21: 149-152.

Trompouki, E., Mullen, L., Fernandez-Reyes, D., Yodoi, J., Kim, S. and Schuettpelz, L.G. 2017.Inflammatory Signaling in Bone Marrow Failure and Hematopoietic Malignancy. Front.immunol. 8: 660.

Vikrant, S., Jaryal, A. and Parashar, A. 2017. Clinicopathological spectrum of snake bite-induced acute kidney injury from India. WId. J. Nephrol.6: 150-161. 